\title{
Formal Analysis of Isothermal Martensite Spread
}

\author{
Paulo Rangel Rios ${ }^{a *}$, José Roberto Costa Guimarães ${ }^{\mathrm{a}, \mathrm{b}}$ \\ ${ }^{a}$ Escola de Engenharia Industrial Metalúrgica de Volta Redonda, \\ Universidade Federal Fluminense - UFF, \\ Av. dos Trabalhadores, 420 27255-125 Volta Redonda - RJ, Brazil \\ ${ }^{\mathrm{b}}$ Mal. Moura 338h/22c 05641-000 São Paulo - SP, Brazil
}

Received: December 4, 2007; Revised: March 19, 2008

\begin{abstract}
A formal kinetic approach was applied to the spread of isothermal martensite over the neighboring austenite grains in a Fe-23.2 wt. (\%) Ni-2.8 wt. (\%) Mn alloy. The number of grains in a spread event changed with parent austenite grain size. However, isothermal martensite spread formed from fine-grained parent austenite and athermal martensite from a Fe-31 wt. (\%) Ni-0.02 wt. (\%) $\mathrm{C}$ alloy studied in a previous work followed the same microstructural path. The number of grains per spread- event found in the present study was shown to be consistent with the number of neighbors of the grain originating the spread event by means of a simple geometrical model of the parent austenite grain network. The study of the kinetics of isothermal martensite spread showed that the nucleation rate of the spread-event in isothermal martensite remained constant during the transformation. This result parallels the constant nucleation rate of the spread-event also found using the same methodology in athermal martensite formed in a Fe-31 wt. (\%) Ni-0.02 wt. (\%) C alloy studied in a previous work.
\end{abstract}

Keywords: martensitic phase transformation, kinetics, microstructure, analytical methods, grain-size effects

\section{Introduction}

Martensite is a displacive phase transformation with significant transformation strains which prompts microstructural heterogeneity, influences plate's shape, and can lead to diversity in kinetics. Usually, the martensite reaction does not start simultaneously in all austenite grains. In bulk polycrystals, the first nucleation event in a single grain may induce transformation in neighboring grains, resulting in a cluster of partially transformed grains. This cluster of partially transformed grains is normally designated as a 'spread event'. The collection of these single spread events can be defined as the 'spread' or 'martensite spread'. The martensite reaction then proceeds by nucleation of additional martensite units within the partially transformed grains, in what is normally called the 'fillin-in'. Martensite nucleation events may take place in a number of grains leading to a certain number of clusters or spreads. In athermal martensite this nucleation takes place very fast at a certain temperature, as a consequence spread and fill-in are completed almost instantaneously. By contrast, in isothermal martensite, nucleation of new martensite plates in untransformed grains and the consequent spread event takes place as a function of reaction time. As a consequence, in isothermal martensite, martensite spread can be followed as function of time.

The microstructure of the martensitic spread is described by the volume fraction of material in grains partially transformed, $\mathrm{V}_{\mathrm{v}}^{\mathrm{g}}$ (not the martensite volume fraction) and by the area of interface between a cluster of partially transformed grains and the untransformed parent matrix, per unit volume of material, $S_{v}^{\mathrm{g}}$. All symbols used in this paper are defined in Table 1 for convenience. The martensite burst is the classical example of autocatalytic spread of martensite over a large number of neighboring austenite grains in a single event. An optical photomicrograph of a Fe-31 wt. (\%) Ni-0.01 wt. (\%) C alloy partially transformed by cooling to its burst temperature, $\mathrm{M}_{\mathrm{B}} \approx 220 \mathrm{~K}$, is shown in Figure 1. Clusters of partially transformed grains in a matrix of untransformed grains are conspicuous.

The martensitic spread in materials that isothermally transform to plate martensite at sub-zero temperatures is the topic of this communication. The current analysis is based on plate martensite formation in alloys of high Ni and high Ni plus Mn contents with sub-zero transformation temperatures. The present analysis does not apply to lath martensite formation in $\mathrm{Fe}-\mathrm{C}$ alloys or steels with high $\mathrm{M}_{\mathrm{s}}$ temperatures.

In a recent paper $^{1}$, the present authors have shown that the methodology of formal kinetics was useful to deal with spread in athermal martensite. The basis of formal kinetic modeling is the early work of Johnson-Mehl' ${ }^{2}$ Avrami $^{3}$ and Kolmogorov ${ }^{4}$ (JMAK ), which used only a single microstructural descriptor, $\mathrm{V}_{\mathrm{V}}$. JMAK's work was subsequently extended by DeHoff and Gokhale's microstructural path method (MPM $)^{5-8}$, who proposed the use of an additional microstructural descriptor, $\mathrm{S}_{\mathrm{v}}$, and the associated concept of microstructural path. Vandermeer and coworkers ${ }^{9}$ extended DeHoff's microstructural path concept and crystallized it in an all round theoretical treatment covering variable nucleation and growth rates as well as non-spherical regions: the microstructural path method (MPM).

The microstructural path method was originally developed to deal with recrystallization and later applied also to diffusional transformations and grain growth but it is in fact quite general and can in principle be used to model any heterogeneous transformation.

In this work, the evolution of spread during isothermal martensite transformation is modeled with the help of the formal kinetics methodology. The theoretical results will be checked with experimental data obtained from Fe-23.2 wt. (\%) Ni-2.8 wt. (\%) $\mathrm{Mn}^{10,11}$ isothermally transformed.

Martensite reaction is nucleation-controlled. Preferred nucleation sites are postulated to exist dormant in the material and propagate the pioneer nucleation event in untransformed grains under the available chemical driving force. Their potency, however, is not uniformly distributed. The reaction inherits this heterogeneity and it is firstly observed only in a few austenite grains ${ }^{12}$. Nonetheless, the pioneer nucleation in a grain has influence over a certain spread volume, $\mathrm{v}_{\mathrm{sp}}$, comprising a number $\gamma$ of austenite grains.

$$
\mathrm{v}_{\mathrm{sp}}=\mathrm{q} \cdot \gamma
$$

*e-mail: prrios@metal.eeimvr.uff.br 
Table 1. List of symbols used in this paper and their definitions.

\begin{tabular}{|c|c|}
\hline Symbol & Definition \\
\hline $\mathrm{M}_{\mathrm{s}}$ & Martensite start temperature; \\
\hline $\mathrm{V}_{\mathrm{v}}$ & Martensite volume fraction; \\
\hline $\mathrm{V}_{\mathrm{v}}^{\mathrm{g}}$ & $\begin{array}{l}\text { Volume fraction of material in grains partially transformed grains, that is, volume fraction of all grains in all } \\
\text { clusters of martensite spread; }\end{array}$ \\
\hline $\mathrm{S}_{\mathrm{v}}^{\mathrm{g}}$ & $\begin{array}{l}\text { Area of interface per unit volume of material between the clusters of partially transformed grains and the } \\
\text { untransformed parent matrix, that is, area of interface per unit volume of martensite spread; }\end{array}$ \\
\hline $\mathrm{V}_{\mathrm{v}, \mathrm{ext}}, \mathrm{V}_{\mathrm{v}, \mathrm{ext}}^{\mathrm{g}}, \mathrm{S}_{\mathrm{v}, \mathrm{ext}}^{\mathrm{g}}$ & $\begin{array}{l}\text { The subscript ext added to these quantities mean that they are extended quantities, that is, that they are calculated } \\
\text { ignoring impingement among growing regions. }\end{array}$ \\
\hline $\mathrm{v}_{\mathrm{sp}}$ & $\begin{array}{l}\text { Volume of a single cluster of austenite grains partially transformed to martensite comprising a number } \gamma \text { of } \\
\text { austenite grains, that is, volume of a single spread event; }\end{array}$ \\
\hline $\mathrm{s}_{\mathrm{sp}}$ & $\begin{array}{l}\text { Surface area between a single cluster of austenite grains partially transformed to martensite and the untransformed } \\
\text { matrix grains, that is, surface area of a single spread event; }\end{array}$ \\
\hline $\mathrm{k}$ & Shape factor related to a single spread event or cluster of partially transformed austenite grains; \\
\hline$\gamma$ & Number of grains in a cluster of partially transformed austenite grains that constitute a spread event; \\
\hline a & Coefficient obtained from microstructural path, $a=2 \gamma^{-1 / 3}$; \\
\hline $\mathrm{N}_{\mathrm{v}}^{\mathrm{m}}$ & Number of austenite grains per unit volume in the parent austenite matrix; \\
\hline $\mathrm{q}$ & Average austenitic grain volume, $\mathrm{N}_{\mathrm{v}}^{\mathrm{m}}=1 / \mathrm{q}$; \\
\hline $\mathrm{d}$ & Grain diameter, $\mathrm{d}=(6 \mathrm{q} / \pi) 1 / 3$ \\
\hline $\mathrm{S}_{\mathrm{v}}^{\mathrm{m}}$ & Grain boundary area per unit volume of parent austenite matrix grains; \\
\hline$\lambda$ & Mean intercept length of parent austenite matrix intercept, $S_{v}^{m}=2 / \lambda$; \\
\hline $\mathrm{n}_{\mathrm{v}}$ & Total number per unit volume of active nuclei at a certain temperature; \\
\hline $\mathrm{n}_{\mathrm{v}}^{\mathrm{i}, \mathrm{T}}$ & Initial density of pre-existent, dormant sites at a certain temperature; \\
\hline $\mathrm{n}_{\mathrm{v}}^{\mathrm{Ms}}$ & Value of $n_{v}$ at $M_{s}$ temperature; \\
\hline $\mathrm{n}_{\mathrm{v}}^{\Delta \mathrm{T}}$ & Number of pre-existent nucleation sites at $\Delta \mathrm{t}=\mathrm{M}_{\mathrm{s}}-\mathrm{T}$, where $\mathrm{T}$ is the transformation temperature; \\
\hline $\mathrm{I}_{\mathrm{v}}$ & Nucleation rate, $\mathrm{I}_{\mathrm{v}}(\mathrm{t})=\frac{\mathrm{dn}_{\mathrm{v}}(\mathrm{t})}{\mathrm{dt}}$ \\
\hline $\mathrm{t}_{0}$ & Incubation time; \\
\hline $\mathrm{m}$ & Volume fraction of martensite in a single grain resulting from the first martensite plate to form; \\
\hline$\alpha, \beta, \mathrm{R}$ & $\begin{array}{l}\text { Parameters of linear regression: } \frac{1}{\gamma \cdot \mathrm{q}} \ln \left(\frac{1}{1-\mathrm{V}_{\mathrm{v}}^{\mathrm{g}}(\mathrm{t})}\right)=\alpha+\beta \mathrm{t}, \alpha \text { is the intercept and } \beta \text { is the slope of the straight } \\
\text { line, } \mathrm{R} \text { is the correlation coefficient; }\end{array}$ \\
\hline
\end{tabular}

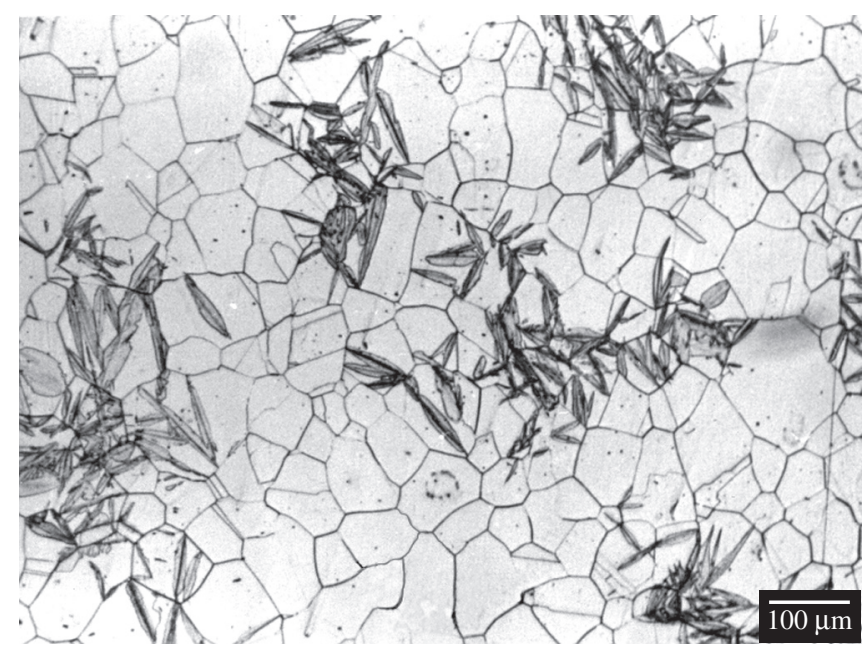

Figure 1. Optical micrograph of a Fe-31 wt. (\%) Ni-0.01 wt. (\%) C alloy transformed at $\mathrm{M}_{\mathrm{s}}(220 \mathrm{~K})$. The martensitic 'spread' can be clearly seen against the background of austenite grains. where $q$ is the average austenitic grain volume, $q=1 / \mathrm{N}_{v}^{m}$ where $\mathrm{N}_{\mathrm{v}}^{\mathrm{m}}$ is the number of austenite grains per unit volume. The transformation continues by subsequent "spread events" that spread the reaction to the untransformed grains.

\section{Experimental Data}

The data used here were obtained by quantitative metallographic techniques to determine volume fraction and interface area per unit of volume from planar sections. The highly pure FeNiC and FeNiMn alloys were reacted under strict control as described in the referenced papers. The authors ${ }^{10,11}$ have described and discussed their experimental conditions at length and that will not be repeated here for brevity. However, for the present work, the data were compiled by scanning and digitizing their graphs with relevant metallographic quantities. Non-conspicuous data points were dismissed. These data were consolidated by reiteration to average out small variations. In the following, FeNiC refers to Fe-31 wt. (\%) Ni-0.02 wt. (\%) C and FeNiMn refers to $\mathrm{Fe}-28$ wt. (\%) Ni-3 wt. (\%) Mn. $\mathrm{S}_{\mathrm{v}}{ }^{\mathrm{m}}$ was obtained from the mean intercept length with the well-known ${ }^{13}$ stereological relation- 
ship $\mathrm{S}_{\mathrm{v}}{ }^{\mathrm{m}}=2 / \lambda$. The values of $\mathrm{q}$ were calculated from $\lambda$ assuming that parent austenite grains can be approximated by tetrakaihedra ${ }^{13}$ (See Figure 4 and discussion in Section 5.): $q=2.34 \lambda^{3} ; d$, the diameter of a sphere with a volume equal to the grain volume, can be found by $d=(6 q / \pi)^{1 / 3}$. The values of $\lambda, S_{v}{ }^{m}, q$ and $d$ are listed in Table 2 for the FeNiMn alloy. In his original work, Ghosh ${ }^{10,11}$ gives the mean intercept length, $\lambda$, for each alloy.

\section{Microstructural Path Analysis}

The MPM describes the transformation in extended space. The extended quantities are transformed into real measurable quantities by means of the fundamental relationships

$$
\begin{gathered}
\mathrm{V}_{\mathrm{v}}^{\mathrm{g}}=-\exp \left(-\mathrm{V}_{\mathrm{v}, \mathrm{ext}}^{\mathrm{g}}\right) \\
\frac{\mathrm{S}_{\mathrm{v}}^{\mathrm{g}}}{1-\mathrm{V}_{\mathrm{v}}^{\mathrm{g}}}=\mathrm{S}_{\mathrm{v}, \mathrm{ext}}^{\mathrm{g}}
\end{gathered}
$$

where $S_{\mathrm{v}, \mathrm{ext}}^{\mathrm{g}}$ and $\mathrm{V}_{\mathrm{v}, \mathrm{ext}}^{\mathrm{g}}$ are extended quantities.

Rios and Guimarães ${ }^{1}$ have derived an expression for the microstructural path of the athermal martensite spread. They assumed a relationship between the volume and surface area of the individual spread, $\mathrm{v}_{\mathrm{sp}}$ and $\mathrm{s}_{\mathrm{sp}}$, respectively. This relationship is ${ }^{9}$

$$
\mathrm{S}_{\mathrm{sp}}=\mathrm{kv}_{\mathrm{sp}}^{2 / 3}
$$

where $k$ is a shape factor. For a tetrakaihedron shape ${ }^{13}$ one obtains $k \cong 5.31$ whereas for a sphere: $k \cong 4.8$. In extended space, $\mathrm{n}_{\mathrm{v}}$ is defined as the total number per unit volume of nuclei which have become active during cooling to the temperature of interest. Using $n_{v}$, the extended quantities are given by $V_{v, e x t}^{g}=v_{s p} n_{v}$ and $S_{v, e x t}^{g}=s_{s p} n_{v}$. Inserting these into Equation 4 results in

$$
\mathrm{S}_{\mathrm{v}, \mathrm{ext}}^{\mathrm{g}}=\mathrm{kv}_{\mathrm{sp}}^{-1 / 3} \mathrm{~V}_{\mathrm{v}, \mathrm{ext}}^{\mathrm{g}}
$$

Equation 5 is the microstructural path in extended space. It can be converted to the microstructural path in real space with the help of Equations 2 and 3

$$
\frac{\frac{S_{v}^{g}}{S_{v}^{m}}}{1-V_{v}^{g}}=a \cdot \ln \left(\frac{1}{1-V_{v}^{g}}\right)
$$

where $S_{v}^{m}$, the total area of austenite grain boundaries per unit of volume of material. The constant $\mathrm{a}=\mathrm{kv}_{\mathrm{sp}}^{-1 / 3} / \mathrm{S}_{\mathrm{v}}^{\mathrm{m}}$ can be simplified assuming that the parent austenite grains can be approximated by tetrakaihedra ${ }^{13}$ $\mathrm{S}={ }_{\mathrm{v}}^{\mathrm{m}} 2.6\left(\mathrm{~N}_{\mathrm{v}}^{\mathrm{m}}\right)^{1 / 3}$ and remembering that $\mathrm{V}_{\mathrm{sp}}=\gamma\left(\mathrm{N}_{\mathrm{v}}^{\mathrm{m}}\right)^{-1}$.

The parameter $a$ in Equation 6 depends only on $\gamma$, which on its turn depend on the parameter $k$. The parameter $k$ is a function of the shape of the spread volume. One possible assumption, adopted in our earlier paper was that the spread volume had a tetrakaidecahedral shape, thus leading to

$$
\mathrm{a}=2 \gamma^{-1 / 3}
$$

Table 2. Fe-28 wt. (\%) Ni-3 wt. (\%) Mn for Ghosh ${ }^{10,11}$ - isothermally transformed at $153 \mathrm{~K}-\gamma, \gamma_{\mathrm{s}}, \mathrm{I}_{\mathrm{v}}$ and $\mathrm{t}_{0, \text { lower }}$ obtained from the analysis of experimental data.

\begin{tabular}{crcccccc}
\hline $\begin{array}{c}\lambda \\
\mathrm{mm}\end{array}$ & $\begin{array}{c}\mathrm{S}_{\mathrm{v}}^{\mathrm{m}} \\
\mathrm{mm}^{-1}\end{array}$ & $\begin{array}{c}\mathrm{d} \\
\mathrm{mm}\end{array}$ & $\begin{array}{c}\mathrm{q} \\
\mathrm{mm}^{3}\end{array}$ & $\gamma$ & $\gamma_{\mathrm{s}}$ & $\begin{array}{c}\mathrm{I}_{\mathrm{v}} \\
\mathrm{mm}^{-3} / \mathrm{s}\end{array}$ & $\begin{array}{c}\mathrm{t}_{0, \text { lower }} \\
(\mathrm{s})\end{array}$ \\
\hline 0.019 & 105.0 & 0.031 & $1.610^{-5}$ & 68 & 50 & 0.5 & 1412 \\
0.048 & 41.7 & 0.079 & $2.610^{-4}$ & 19 & 14 & 1.7 & 417 \\
\hline
\end{tabular}

Another possibility would be to assume a spherical shape and in this case

$$
\mathrm{a}=1.8 \gamma_{\mathrm{s}}^{-1 / 3}
$$

where the subscript 's' in $\gamma_{\mathrm{s}}$ is meant to emphasize that it was obtained from the assumption of a spherical shape. A relationship between $\gamma_{\mathrm{s}}$ and $\gamma$ can be easily found: $\gamma_{\mathrm{s}} \cong 0.73 \gamma$. We will use $\gamma$ throughout this paper for consistency with previous work but for comparison purposes it is also interesting to have $\gamma_{\mathrm{s}}$.

It is worthy of note that the derivation of Equation 6 did not make any specific kinetic assumptions concerning athermal martensite but only assumptions regarding the spread volume, Equation 1. Therefore, Equation 6 should also be applicable for isothermal martensite and possibly to mechanically induced martensite as well. Figure 2 confirms that the experimental data can be well described by the microstructural path, Equation 6.

Both isothermal sets of data plotted after Equation 6 can be described by a best-fit straight line passing through the origin with a slope a equal to 0.49 for $\mathrm{d}=0.031 \mathrm{~mm}$ and a equal to 0.75 for $\mathrm{d}=0.079 \mathrm{~mm}$, with a high correlation coefficient, $\mathrm{R}=0.98$ and 0.99 , respectively. The values of $\gamma$, calculated using Equation 7 , were equal to $68\left(\gamma_{\mathrm{S}} \approx 50\right)$ for the fine-grained austenite and $19\left(\gamma_{\mathrm{S}} \approx 14\right)$ for the coarse-grained austenite and are listed in Table 2. Previous analysis of athermal martensite in $\mathrm{Fe}-31 \mathrm{wt}$. (\%) Ni-0.02\%C showed that the parameter a was also equal to 0.49 and consequently $\gamma$ was also equal to 68 and independent of grain size. By contrast, in the isothermal transformation analyzed here the values of $\gamma$ depended on the grain size. The reason for this is discussed in section 5 below. For the fine-grained matrix, $d=0.031 \mathrm{~mm}$, the values of $\mathrm{a}=0.49$ and $\gamma=68$ obtained by MPM were identical to those obtained for the athermal martensite in $\mathrm{Fe}-31$ wt. (\%) Ni-0.02\% $\mathrm{C}^{1}$. The data corresponding to the athermal martensite of Fe-31 wt. (\%) Ni-0.02\% $\mathrm{C}^{1,14,15}$ are also included in Figure 2. Notice that the theoretical MPM line is common to both fine-grained isothermal and athermal martensite data since their values of a were identical as already mentioned. Therefore, it is evident from Figure 2 that the fine-grained isothermal and the athermal martensite spreads follow the same microstructural path

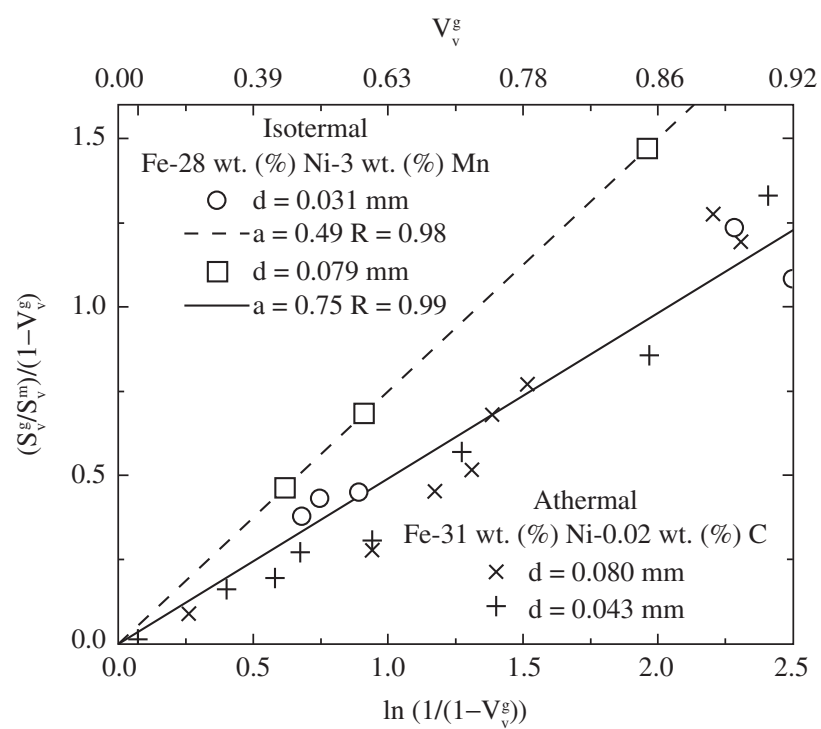

Figure 2. Microstructural path of isothermal martensite spread. The theoretical result, Equation 6, is compared with experimental data from a Fe-23.4 wt. (\%) Ni-2.8 wt. (\%) Mn alloy obtained by Ghosh ${ }^{10,11}$. The correlation coefficient, $\mathrm{R}$, is also shown. The fine-grained isothermal martensite and the athermal martensite follow the same microstructural path. 
regardless of their significant differences in kinetics particularly with regard to the number of martensite units per grain in a spread event ${ }^{10,16}$. This result is remarkable and indicates a basic formal similarity between the special aspects of martensite spreads in such apparently different reactions.

\section{Formal Analysis of Spread Kinetics}

Whereas pioneer isothermal martensite nucleation takes place at the most potent pre-existent nucleation sites, autocatalytic nucleation promoted by the martensite plate in its vicinity has a clear effect on filling-in with martensite units the partially transformed grains and also on poking the reaction into a next grain. In extended space, the number per unit volume of pre-existent nucleation sites which have become active as a function of time at temperature of interest, $n_{v}$, is given by

$$
\operatorname{dn}_{v}(t)=I_{v}(t) d t
$$

or

$$
I_{v}(t)=\frac{d n_{v}(t)}{d t}
$$

where I is rate of that process. It is important to stress that no assumptions are made here concerning the specific time dependence of either $n_{v}$ or $I_{v}$.

However, one must consider that there is an incubation time, $\mathrm{t}_{0}$, at which a pioneer nucleation event takes place at one of the pre-existent nucleation sites. The initial density of these pre-existent, dormant sites is $n_{v}^{i, T}$. Thereafter, follows Eqution 10. Therefore Equation 10 can be rewritten as

$$
\mathrm{n}_{\mathrm{v}}(\mathrm{t})=\mathrm{n}_{\mathrm{v}}^{\mathrm{i}, \mathrm{T}}+\int_{\mathrm{t}_{0}}^{\mathrm{t}} \mathrm{I}_{\mathrm{v}}(\tau) \mathrm{d} \tau
$$

Here, $\gamma$ is considered to remain constant independent of transformation temperature, time or fraction transformed but may depend on grain size. The spread event originated by a pioneer nucleation event propagates until it reaches a volume, $\mathrm{v}_{\mathrm{sp}}$, Equation 1. As a result, $\mathrm{v}_{\mathrm{sp}}$, is assumed to remain constant throughout the transformation. Therefore, the extended volume of spread can be calculated by

$$
\mathrm{V}_{\mathrm{v}, \text { ext }}^{\mathrm{g}}(\mathrm{t})=\mathrm{n}_{\mathrm{v}}^{\mathrm{i}, \mathrm{T}} \mathrm{v}_{\mathrm{sp}}+\int_{\mathrm{t}_{0}}^{\mathrm{t}} \mathrm{v}_{\mathrm{sp}} \mathrm{I}_{\mathrm{v}}(\tau) \mathrm{d} \tau
$$

defining

$$
\mathrm{n}_{\mathrm{v}}^{\mathrm{i}}(\mathrm{t})=\int_{\mathrm{t}_{0}}^{\mathrm{t}} \mathrm{I}_{\mathrm{v}}(\tau) \mathrm{d} \tau
$$

and inserting Equation 13 into Equation 12 gives

$$
\mathrm{V}_{\mathrm{v}, \mathrm{ext}}^{\mathrm{g}}(\mathrm{t})=\gamma \cdot \mathrm{q} \cdot\left(\mathrm{n}_{\mathrm{v}}^{\mathrm{i}, \mathrm{T}}+\mathrm{n}_{\mathrm{v}}^{\mathrm{i}}(\mathrm{t})\right)
$$

introducing equation 14 into equation 2 obtains

$$
\mathrm{V}_{\mathrm{v}}^{\mathrm{g}}(\mathrm{t})=1-\exp \left(-\gamma \cdot \mathrm{q} \cdot\left(\mathrm{n}_{\mathrm{v}}^{\mathrm{i}, \mathrm{T}}+\mathrm{n}_{\mathrm{v}}^{\mathrm{i}}(\mathrm{t})\right)\right)
$$

Eqution 15 can be rearranged and be put in a form more convenient for comparison with experimental data, see below,

$$
\frac{1}{\gamma \cdot \mathrm{q}} \ln \left(\frac{1}{1-\mathrm{V}_{\mathrm{v}}^{\mathrm{g}}(\mathrm{t})}\right)=\mathrm{n}_{\mathrm{v}}^{\mathrm{i}, \mathrm{T}}+\mathrm{n}_{\mathrm{v}}^{\mathrm{i}}(\mathrm{t})
$$

Figure 3 shows that plotting the left hand side of Equation 16 as a function of time results in straight lines of the form

$$
\frac{1}{\gamma \cdot \mathrm{q}} \ln \left(\frac{1}{1-\mathrm{V}_{\mathrm{v}}^{\mathrm{g}}(\mathrm{t})}\right)=\alpha+\beta \mathrm{t}
$$

In these plots, the values of $\gamma$ used, were obtained from MPM analysis, see Table 2.

From these straight lines, $\beta$ can be immediately recognized to be equal to the nucleation rate, $\mathrm{I}_{\mathrm{v}}$. Unfortunately, one cannot extract the values of $\mathrm{n}_{\mathrm{v}}^{\mathrm{i}, \mathrm{T}}$ and $\mathrm{t}_{0}$ from this regression. This problem can be better understood rewriting the right hand side of Equation 16, using, $I_{v}=\beta$ and comparing it with Equation 11

$$
\alpha=\mathrm{n}_{\mathrm{v}}^{\mathrm{i}, \mathrm{T}}-\mathrm{I}_{\mathrm{v}} \mathrm{t}_{0}
$$

It can be seen from Equation 18 that there are two unknowns: $\mathrm{n}_{\mathrm{v}}^{\mathrm{i}, \mathrm{T}}$ and $\mathrm{t}_{0}$ and only one experimental parameter, $\alpha$. Under these circumstances, one may obtain only a lower bound for the incubation time, $\mathrm{t}_{0, \text { lower }}$, by setting the volume fraction of partially transformed grains equal to zero

$$
\mathrm{t}_{0, \text { lower }}=\mathrm{t}_{0}-\frac{\mathrm{n}_{\mathrm{v}}^{\mathrm{i}, \mathrm{T}}}{\mathrm{I}_{\mathrm{v}}}=\frac{-\alpha}{\mathrm{I}_{\mathrm{v}}}
$$

The actual $\mathrm{t}_{0}$ will be larger than $\mathrm{t}_{0, \text { lower }}$ because $\mathrm{n}_{\mathrm{v}}^{\mathrm{i}, \mathrm{T}}>0$. The calculated values of $\mathrm{t}_{0 \text {,lower }}$ are given in Table 2 . In diffusional reactions, a nucleation event generates a very small volume of the product phase which then grows relatively slowly. However, in martensitic reactions, once a nucleus is activated a plate grows nearly instantaneously to its final size. As a consequence, a finite volume fraction of martensite and also of partially transformed grains become instantaneously greater than zero at $t \geq t_{0}$ whereas the volume fraction of martensite is equal to zero for $t<t_{0}$.

\section{Discussion}

As early as 1887 , Thomson (Lord Kelvin) ${ }^{17}$ proposed that the truncated octahedron or tetrakaidecahedron network would provide a space-filling arrangement of similar cells of equal volume with a minimal interface area. This problem is still of interest to this day ${ }^{18}$. In Metallurgy one often adopts Kelvin's network as an approximation for the polycrystalline structure. We will use such an approximation here to offer a geometric interpretation of the values of $\gamma$ found from the above analysis.

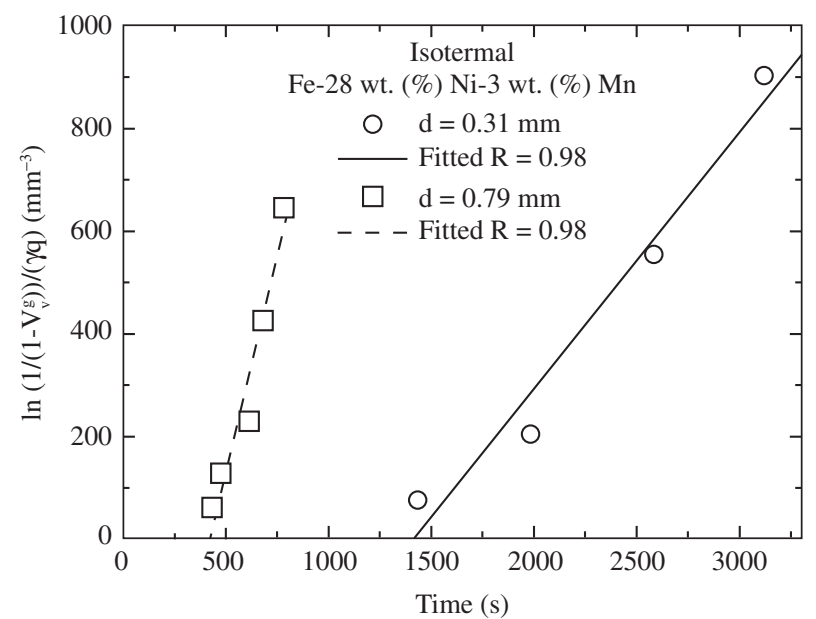

Figure 3. Isothermal martensite experimental data from a Fe-23. wt. (\%) Ni-2.8 wt. (\%) Mn alloy obtained by Ghosh ${ }^{10,11}$ plotted after Equation 17. The correlation coefficients, $\mathrm{R}$, are also shown. 
The basic unit of Kelvin's network is the truncated octahedron that is depicted in Figure 4. It is a polyhedron possessing fourteen faces, eight hexagonal faces and six square faces. In order to fill space they must be packed in a body centered cubic structure. The BCC unit cell with nine truncated octahedra is shown in Figure 5. The polyhedron located at the center of the BCC cell shares a hexagonal face with each polyhedra located at the vertices. A full cluster consisting of 15 truncated octahedral is shown in Figure 6. The other six polyhedral are

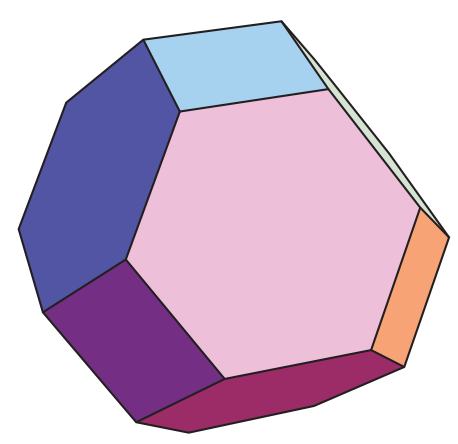

Figure 4. Truncated octahedron or tetrakaidecahedron, the basic unit for a space-filling network, proposed by Thomson ${ }^{17}$. This polyhedron has 14 faces: 8 hexagons and 6 squares.

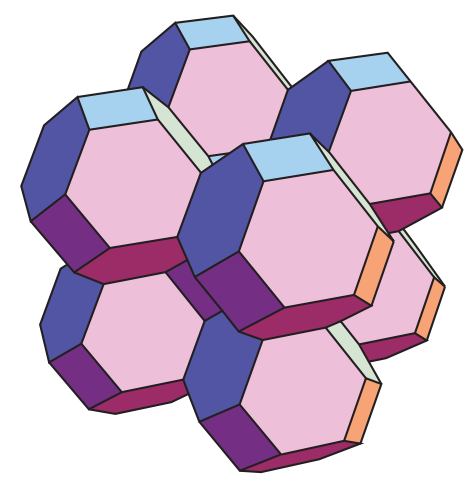

Figure 5. Body centered cubic arrangement of truncated octahedra or tetrakaidecahedra. Space-filling is achieved through BCC packing. The polyhedron located at the center of the BCC cell shares a hexagonal face with each one of the eight polyhedra located at the vertices.

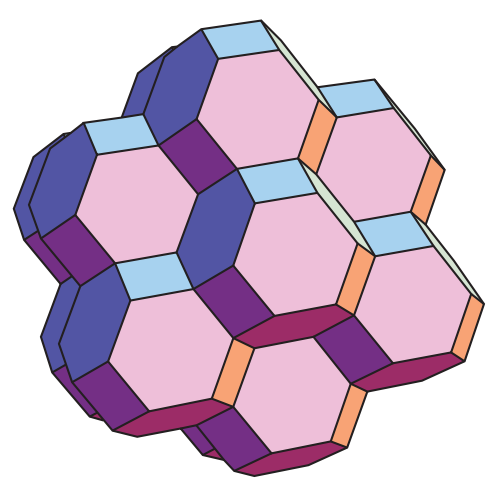

Figure 6. Cluster of 15 truncated octahedra or tetrakaidecahedra, the central polyhedron is surrounded by 14 nearest neighbors. The 9 polyhedra depicted in Figure 5 are joined by 6 polyhedra, which are attached in such a way that they share a square face with the polyhedron located at the center of the BCC cell. Other grains joining this cluster will not have contact with the central grain, which contains the pioneer plate. attached in such a way that they share a square face with the polyhedron located at the center of the BCC cell. These six polyhedra occupy the center of adjacent BCC cells. If all polyhedra on these adjacent cells were counted one would have a cluster with 39 polyhedra. If one went further and completed a cube consisting of twenty seven BCC cells, the number of polyhedra in the cluster would raise to 91 .

These numbers are quite close to the values of $\gamma$ obtained experimentally by means of the MPM methodology. For the isothermal martensite with large grain size, $\gamma$ was about 14-19, suggesting that the spread was essentially limited to the grains in direct contact with the grain in which nucleation started. On the other hand, for fine grained isothermal martensite and also to athermal martensite $\gamma$ was about 50-68, indicating that the spread went beyond the nearest neighbors grains. In this case, plates forming in grains adjacent to the grain containing the pioneer plate might also have been able to induce nucleation on their first neighbors thus increasing the number of grains of the spread. Therefore, the experimental result and its geometrical interpretation are quite consistent. Based on this one might suggest that the number of grains in the spread should be somewhere between the cluster formed by the first neighbors with 15 grains and the cluster formed by the cube of $27 \mathrm{BCC}$ cells with 91 grains.

In order to explain the different microstructural path of coarsegrained isothermal martensite when compared to the fine-grained isothermal and athermal martensite, consideration must be given to the fact that plates that outright run across and transform a larger volume fraction of a grain have a more significant effect on its surroundings, as it is observed with the "bursting" FeNiC alloy ${ }^{15}$. This is seen in Figure 7 where the number of grains comprising a spread event, $\gamma$, is plotted against the grain volume fraction transformed by the first plate to form, $\mathrm{m}=\mathrm{v} / \mathrm{q}$, where $\mathrm{v}$ is the volume of a grain's pioneer plate. This is in apparent contempt with the fact that in isothermally transformed FeNiMn, a coarser grain size has an adverse effect on $\mathrm{m}^{16}$, hence on $\gamma$, Table 2. However, when plate and grain size are tuned, such as promoted in FeNiMn by a finer grained condition, the values of $\gamma$ in the "isothermal spread" become similar to FeNiC's "athermal spread" as shown in Figure 2. This also supports the view that plate impingement on grain boundaries has a key role in the spread of the martensite reaction ${ }^{16}$.

In spite of the obvious differences between athermal and isothermal martensite, the former transforms as a function of temperature and

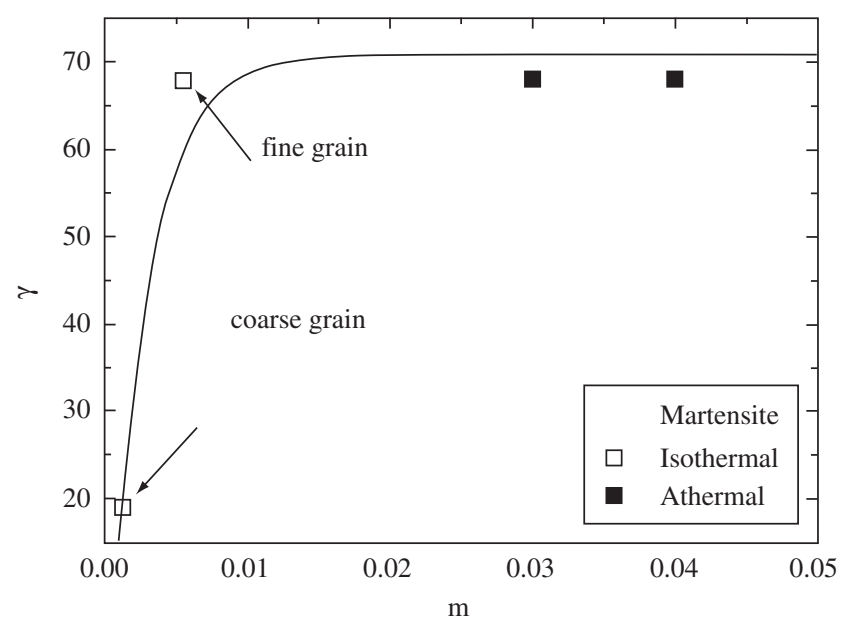

Figure 7. $\gamma$, i. e., the number of grains of the spread event or cluster of partially transformed grains of the parent matrix plotted against $\mathrm{m}$, the ratio of the volume of a pioneer plate, $v$, to the grain volume, $\mathrm{q}^{16}$. Values of $\gamma$ for Fe-23.4 wt. (\%) Ni2.8 wt. (\%) Mn, isothermal martensite, were obtained from Table 2. For Fe-31 wt. (\%) Ni-0.02 wt. (\%) C, athermal martensite, $\gamma$ was taken from previous work ${ }^{1}$. The solid line depicted in the figure is just a guideline, not a theoretical result. 
latter as a function of time, the present formalism revealed interesting similarities with regard to the martensitic spread in both cases.

The first similarity concerns the microstructural path of both reactions. Both follow Equation 6, moreover, fine-grained isothermal and the athermal martensite spreads followed the same microstructural path, a remarkable result, considering their very different kinetics particularly with regard to the number of martensite units per grain in a spread event. This suggests a basic geometric likeness between the martensitic spread in both reactions.

The second similarity pertains to the kinetics of spread. In a previous work, we analyzed the spread kinetics with a formalism identical to that used in section 4 and obtained a relationship that closely resembles Equation 16

$$
\frac{1}{\gamma \cdot \mathrm{q}} \ln \left(\frac{1}{1-\mathrm{V}_{\mathrm{v}}^{\mathrm{g}}(\mathrm{T})}\right)=\mathrm{n}_{\mathrm{v}}^{\mathrm{Ms}}+\mathrm{n}_{\mathrm{v}}^{\Delta \mathrm{T}}\left(\mathrm{M}_{\mathrm{s}}-\mathrm{T}\right)
$$

Where now $\mathrm{n}_{\mathrm{v}}^{\mathrm{Ms}}$ pertains to the martensite start temperature, and $\mathrm{n}_{\mathrm{v}}^{\Delta \mathrm{T}}$ represents the number of pre-existent nucleation sites that become available as the transformation temperature decreased from $\mathrm{M}_{\mathrm{s}}$ to $\mathrm{T}$. Notice that athermal martensite starts with a burst at $\mathrm{M}_{\mathrm{s}}$. Therefore $\mathrm{M}_{\mathrm{s}}$, that is normally known, is our 'incubation temperature', which eliminates the issue of incubation time. When Equation 20 was plotted against temperature, straight lines like Equation 17 with temperature substituted for time where obtained (See Figure 2 of Rios and Guimarães) $)^{1}$.

$$
\frac{1}{\gamma \cdot \mathrm{q}} \ln \left(\frac{1}{1-\mathrm{V}_{\mathrm{v}}^{\mathrm{g}}(\mathrm{T})}\right)=\mathrm{n}_{\mathrm{v}}^{\mathrm{Ms}}+\Gamma_{\mathrm{v}} \cdot\left(\mathrm{M}_{\mathrm{s}}-\mathrm{T}\right)
$$

From Equation $21 \Gamma_{\mathrm{v}}$ could be identified as a constant nucleation temperature rate of the athermal spread event (increase in number of nuclei or pioneer plates per unit of volume per unit of temperature ). The meaning of both athermal and isothermal spread events having a constant nucleation rate requires further investigation.

\section{Summary and Conclusions}

The formalism proposed here was able to account for the microstructural path and the evolution of the volume fraction of partially transformed grains, $\mathrm{V}_{\mathrm{v}}^{\mathrm{g}}$, as a function of time for the isothermal martensite transformation in the Fe-23.4 wt. (\%) Ni-2.8 wt. (\%) Mn alloy ${ }^{10,11}$ analyzed here.

From the microstructural path itself, Equation 6 and Figure 2, it could be shown that the number of grains of the spread event or cluster of partially transformed grains of the parent matrix, $\gamma$, depends on the grain size of the parent austenite. However, as shown in Figure 2, the spread of isothermal martensite of the Fe-23.4 wt. (\%) Ni-2.8 wt. (\%) Mn alloy from fine-grained austenite and the spread of athermal martensite transformation in a Fe-31 wt. (\%) Ni-0.02 wt. (\%) C alloy followed the same microstructural path. This indicated a basic geometric similarity of the spread in both reactions.

The analysis of the evolution of the volume fraction of partially transformed grains, $\mathrm{V}_{\mathrm{v}}^{\mathrm{g}}$, as a function of time, has shown that the rate of nucleation of pioneer plates per unit of volume, $\mathrm{I}$, remained constant during isothermal transformation. Such constant nucleation rate was also observed in athermal martensite analyzed by an identical formalism in a previous work ${ }^{1}$.

A geometrical interpretation was provided for the values of the number of grains of the spread event or cluster of partially transformed grains of the parent matrix, $\gamma$, showing that the numbers obtained in the analysis are consistent with the number of neighbor grains present in the parent matrix.
In summary, the formalism used here, likewise previous analysis conducted for athermal martensite transformation ${ }^{1}$, was able to describe quite well the isothermal martensite spread. Striking similarities between athermal and isothermal martensite with regard to the microstructural path and nucleation rate of the spread event in both reactions were revealed.

\section{Acknowledgments}

One of the authors (P. R. RIOS) is grateful to Conselho Nacional de Desenvolvimento Científico e Tecnológico, CNPq, and to Fundação de Amparo à Pesquisa do Estado do Rio de Janeiro, FAPERJ, for his financial support.

\section{References}

1. Rios PR, Guimarães JRC. Microstructural path analysis of athermal martensite. Scripta Materialia. 2007, 57(12):1105-1108.

2. Johnson WA, Mehl RF. Reaction kinetics in processes of nucleation and growth. Transactions AIME. 1939, 135: 416-441.

3. Avrami MJ. Kinetics of phase change I general theory. The Journal of Chemical Physics. 1939, 7(12): 1103-1112.

4. Kolmogorov AN. On the statistical theory of metal crystallization. In Selected works of Kolmogorov A N, edited by Tikhomirov V M [Translated from the Russian by Volosov V M]. Dordrecht: Kluwer Academic; 1991. p.188-192.

5. Gokhale AM, Iswaran CV and DeHoff RT. Use of the stereological counting measurements in testing theories of growth-rates. Metallurgical Transactions A. 1979, 10A(9): 1239-1245.

6. Gokhale AM. Use of stereological measurements for the study of grainboundary diffusion controlled precipitate growth-kinetics. Metallurgical Transactions A. 1985, 16A(3): 456-457.

7. Gokhale AM. Application of microstructure modeling to the kinetics of proeutectoid ferrite transformation in hot-rolled microalloyed steels. Metallurgical Transactions A. 1986, 17A(9): 1625-1629.

8. DeHoff RT. In: Hansen N, Jensen DJ, Leffers T; Ralph B, editors Annealing Processes-Recovery, Recrystallization and Grain Growth, Proceedings of the $7^{\text {th }}$ Conference of Ris $\varnothing$ National Laboratory; 1986, Roskilde, Denmark. Roskilde: Ris $\emptyset$ National Laboratory. 1986; 35-52.

9. Vandermeer RA, Masumura RA, Rath B. Microstructural paths of shapepreserved nucleation and growth transformations. Acta Metallurgica et Materialia. 1991, 39(3): 383-389.

10. Ghosh G. Spread of transformation and plate dimensions of isothermally formed martensite. Materials Science and Engineering 1988, 101: 213-220.

11. Ghosh G. Northwestern University, Evanston, USA, 2007, personal communication.

12. Raghavan V. Formation sequence of plates in isothermal martensite transformation. Acta Metallurgica. 1969, 17(10): 1299-1303.

13. Hilliard JE and Lawson LR. Stereology and Stochastic Geometry. Dordrecht: Kluwer Academic Publishers; 2003.

14. Guimarães JRC and Gomes JC. Metallographic study of influence of austenite grain-size on martensite kinetics in Fe-31.9 Ni-0.02C. Acta Metallurgica. 1978, 26(10): 1591-1596.

15. Guimarães JRC and Saavedra AA computer-assisted analysis of the spread of martensite-transformation. Materials Science and Engineering. 1984, 62(1): 11-15.

16. Guimarães JRC. Isothermal martensite: the austenite grain-size and the kinetics of "spread". Materials Science and Technology. 2007, DOI: 10.1179/174328407X226734, in press.

17. Thomson W. (Lord Kelvin) On the division of space with minimum partitional area. Philosophical Magazine. 1887, 24(151): 503-514.

18. Glicksman ME and Rios PR. Minimal network partitions using average N-hedra. Philosophical Magazine. 2007, 87(2): 189-208. 